\title{
COMPUTER-BASEd COURSEWARE FOR TEACHING Communication Skills in Health Care
}

\section{TO THE EDITOR}

Communication skills is a topic which is usually addressed in all departments of the Faculty of Health Sciences so that learners have at their disposal a comprehensive knowledge of communication and the doctor-patient relationship. At the School of Medicine of the University of the Free State the learners used to receive a lecture on communication skills as part of community based education where the students witnessed a consultation and had to report on the communication process. This consultation was not standardised and as the assessor was not present at the consultation he/she could not give a valid or appropriate comment on the remark/report of the learner. An additional problem for some learners was that often the consultation took place in a language they could not understand and therefore could not assess the communication process. The above problems were solved by developing a computer-based courseware and a video of a simulated consultation for instruction in communication skills.

In the computer-based courseware learners first attend formal lectures on communication skills. The contents include: effective communication; factors influencing communication; communicating with patients; doctor-patient relations, communication, co-operation; inter-professional communication; and patient-centred medical care. After the lectures they have to complete the computer-based part during scheduled hours/or in their own time. The computer-based courseware consists of 3 tasks and a test. The student interface is hosted in WebCT. The aim and instructions, tasks and test, as well as the memorandum for the test, are placed as links on the main page.

Task 1 is a summary of the formal lecture. The learners must read the summary to refresh their memory on good communication techniques and what should preferably be avoided.

Task 2 is a summary in the form of a flow chart of the crucial elements in the lecture for quick reference. The learners must use the summary to revise what they have read and heard.

Test 1 follows the two tasks and a questionnaire must be completed for which the learners must earn at least $60 \%$ before they can continue with the courseware to the video assignment. This ensures that the learners have sufficiently mastered the communication process. Marks obtained are instantly available to the learners and they have 3 opportunities to pass

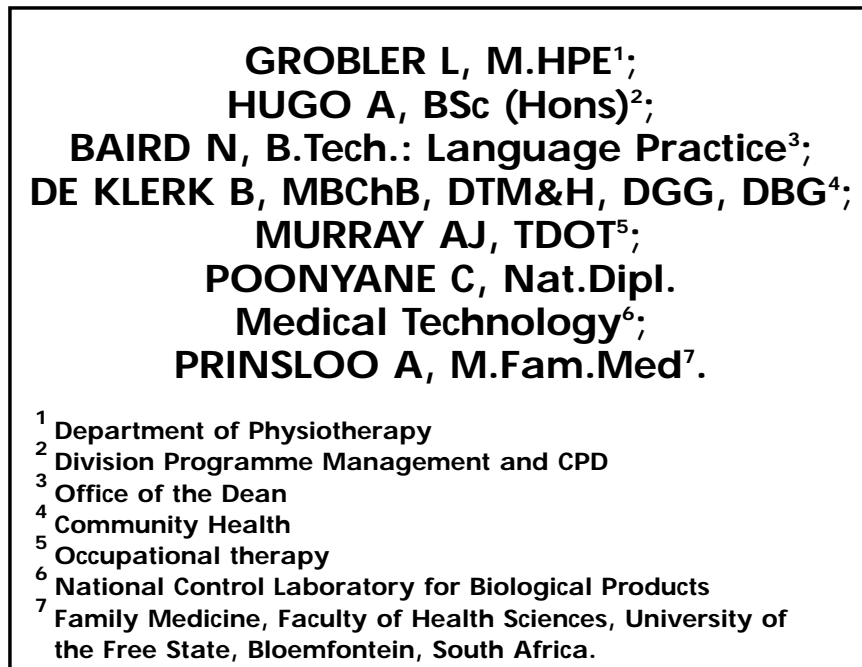

the test. The link to this assignment is only active once they have obtained at least $60 \%$ in the questionnaire.

Task 3 is a written assignment the learners must submit after viewing the video, which demonstrates the correct, incorrect, positive and negative elements of a consultation. An essay of at least 500 words on the communication process in the video must be presented before a pre-determined date. The memorandum to the questionnaire is available after the date on which the written assignment is due. Marks obtained for the written assignment contribute $10 \%$ of the module mark.

The computer-based courseware was implemented successfully in the medical curriculum and in the Department of Physiotherapy (University of the Free State). An interdisciplinary lecturer group developed the courseware and video thereby effectively easing their workload and eliminating unnecessary lecture duplication.

\section{CORRESPONDING AUTHOR:}

Mrs L Grobler

Department of Physiotherapy, Faculty of Health Sciences

University of the Free State

P O Box 339, Bloemfontein, 9300

Tel: (051) 401-3302, Fax: (051) 401-3304

Email: gnftlg.md@mail.uovs.ac.za

All correspondence to the editor must be addressed to:

Prof CJ Eales - Editor SASP Journal,

School of Therapeutic Sciences, Faculty of Health Sciences,

7 York Road, Parktown 2193

E-mail: ealescj@therapy.wits.ac.za, garstanglm@therapy.wits.ac.za 